\title{
Alvarado Score System, how useful is in Emergency Department? Some consideration about it.
}

\author{
Agron Dogjani ( $\nabla$ agrondogjani@yahoo.com ) \\ University Hospital of Trauma https://orcid.org/0000-0003-1275-3336 \\ Kastriot Haxhirexha \\ State University of Tetova \\ Arben Gjata \\ Universiteti i Mjekesise Tirane

\section{Sabina Dogjani} \\ Universiteti i Mjekesise Tirane \\ Hysni Bendo \\ Universiteti i Mjekesise Tirane
}

\section{Research article}

Keywords: Acute Appendicitis, appendectomy, Alvarado Score

Posted Date: December 19th, 2019

DOI: https://doi.org/10.21203/rs.2.19100/v1

License: (c) (i) This work is licensed under a Creative Commons Attribution 4.0 International License.

Read Full License 
Alvarado Score System, how useful is in Emergency Department? Some consideration about it. Agron DOGJANI ${ }^{*}$, Kastriot HAXHIREXHA $^{2}$, Arben GJATA ${ }^{3}$, Sabina DOGJANI ${ }^{4}$, Hysni BENDO ${ }^{4}$.

${ }^{1}$ University Hospital of Trauma, Lecturer at University Medical of Tirana, ALBANIA

${ }^{2}$ General Surgeon at Clinical Hospital of Tetovo, RN of MACEDONIA.

${ }^{3}$ Department of Surgery, University Hospital Center (UHC) "Mother Teresa" Tirana ALBANIA

${ }^{4}$ Resident at University Medical of Tirana, ALBANIA

${ }^{*}$ Corresponding Author: Agron Dogjani MD, MSc, PhD, FACS, FISS.

Associate Professor of Surgery, University Hospital of Trauma, Lecturer at University Medical of Tirana, Albania.

Email; agrondogjani@yahoo.com ; agrondogjani@gmail.com;

Mobile +355692056123

\section{Abstract}

Background; "Acute Appendicitis" is one of the most usual causes of emergency hospital admissions and appendectomy is one of the most common emergency procedures performed in the contemporary medicine.

This study aims to identify the Alvarado Score System as a simplified tool for the emergency doctor in the abdominal emergency in general and for the Acute Appendicitis in particular.

Materials and methods; The study is of retrospective character and includes 130 cases presented with abdominal Pain in University Hospital Centre" Mother Theresa" Tirana, Albania, in the period 1 April 2019 - 30 May 2019 from which 100 allegedly suspected with "Appendicitis Acute".

Results; Gender distribution has a slight male predominance. The predominant age group was 14-21 years old. The most frequent clinical data has been the tenderness in right iliac fossa. In our study 3\% of cases belonged to the group 1-4 Alvarado points, $17 \%$ of the cases belonged to the group 5-6 Alvarado points and $80 \%$ of the cases belonged to the group 7-10 Alvarado points.

Conclusions; In underdeveloped or developing countries where the decision to operate depends on clinical judgment, the Alvarado Score can serve as a precise and consistent tool to exclude Acute Appendicitis. Alvarado Score can also serve the emergency doctor as a tool with predictive value in the abdominal emergency.

Key Words: Acute Appendicitis, appendectomy, Alvarado Score 
Introduction; "Acute Appendicitis" is one of the most common reasons for emergency hospitalization and appendectomy is one of the most common emergency procedures performed in contemporary medicine. (1)

Despite the prevalent role that this organ plays today in healthcare, human appendix was not discovered until 1492. Leonardo da Vinci presented it in his anatomical drawings, but they were not discovered until the 18th century. (2) In 1521 Berengario Da Capri and in 1543 Andreas Vesalius published drawings documenting the appendix. (3)

The first appendectomy was performed in 1736 by Claudius Amyand in London. He operated on an 11-year-old boy with inguinal hernia and fecal fistula. Within the herniated sac, he discovered a perforated appendix surrounded by the omentum. The appendix and omentum were removed. (4)

The incidence of appendicitis gradually increases from birth, peaks in late adolescence, and gradually decreased in the geriatric period. All ages can be affected but the highest incidence is observed at 1020 years of age while this incidence is low in children under 3 years of age. (5) The median age when appendicitis occurs in the pediatric population is 6-10 years. Lymphoid hyperplasia is more commonly observed in children and adolescents and is responsible for the increased incidence in these age groups. (5)

There is no unified hypothesis to explain the etiology of Acute Appendicitis (AA) alone, but it is known that the obstructive role of the appendiceal lumen plays a major role. The cause of lumen obstruction are fecaliths, lymphoid hyperplasia, foreign bodies, parasites, tumors, etc. $(5,6)$.

The inflammatory process of appendicitis presents with pain, which initially begins as a diffuse visceral pain and later becomes localized somatic pain when the peritoneum is affected. Physical examination of the patient is performed with the patient lying in the dorsal decubitus, with his legs flexed. It is crucial in establishing the diagnosis of AA. (7)

The differential diagnosis of AA is practically the diagnosis of an acute abdomen. A similar clinical picture may result from many acute processes within the peritoneal cavity producing the same physiological alterations as AA. $(6,8)$

Although surgery remains the standard treatment used for AA, there are a growing number of studies supporting the idea of conservative treatment in patients with uncomplicated AA. (7)

The natural history of appendicitis is unclear. The risk of perforation is mainly observed in younger ( $<5$ years) and elderly ( $>65$ years). There is also the possibility of spontaneous resolution and as a result we can say that perforated and non-perforated appendicitis can also be considered as different diseases. $(5,9)$

The mortality rate ranges from $0.2 \%$ to $0.8 \%$ and is associated more with the complications of the disease rather than the surgery itself. $(8,10)$ 
Despite the diagnostic advancement in medicine, Acute Appendicitis remains a clinical emergency and one of the leading causes of acute abdominal pain. (5)

Purpose of the article is to identify the Alvarado scoring system as a simplified tool for the emergency physician to identify patients in need of surgical consultation in the abdominal emergency in general and AA in particular. The overall objectives of the article are: to present the epidemiological distribution of AA; to recognize and to assess the symptoms, local signs and major laboratory findings of AA. The specific objectives of the article are to determine an appropriate criterion for the Alvarado system so it can increase its predictive value for AA

Methodology; The study is retrospective in nature and contains both descriptive and analytical components. Epidemiological data, symptoms, local signs, and laboratory findings for each case included in the study were described. Two criteria based on Alvarado scores points were also proposed and it was analyzed which of them had the highest diagnostic accuracy to predict AA.

Material and method; This study includes 130 cases presented with Abdominal Pain in the surgical emergency of University Hospital Centre (UHT) " Mother Theresa" Tirana, Albania, in the period April 1, 2019 - May 30, 2019. Of the 130 patients initially included in the study, 100 were given the diagnosis suspect AA and underwent surgery.

The study focused on these 100 cases that underwent surgery as suspect AA. Patients belong to different age groups. The male / female ratio was approximately 1: 1, exactly 52 males and 48 females. All 100 patients who had a suspected AA outcome underwent surgical intervention and cases were confirmed by macroscopic examination of the surgical specimen. (Although a completely safe diagnosis would be made by histological examination, such data were missing in the patients' files).

Study variables that were obtained from clinical card data include: Gender (Male, Female); age group (14-21 years old; 21-31 years old; 41-61 years old); Symptoms (Migratory pain in the right iliac fossa; Anorexia; Nausea and vomiting); Local Signs [Muscular protection in the right iliac fossa; Blumberg's sign (sensitivity restoring after pressure lift), Increased temperature]; Laboratory findings (leukocytosis; Left shift of the leukocyte formula); Alvarado scoring result.(11) (See table 1)

Alvarado score was calculated for all patients presented, based on patient-reported symptoms, signs evidenced by physical examination, and their laboratory data.

Table 1. Summary of variables (11)

\begin{tabular}{|l|l|c|}
\hline Variables & Sub variables & Points \\
\hline \multirow{4}{*}{ Symptoms } & $\begin{array}{l}\text { Migratory pain in the right iliac fossa } \\
\text { (Kocher Sign) }\end{array}$ & 1 \\
\cline { 2 - 3 } & Anorexia & 1 \\
\cline { 2 - 3 } & Nausea and vomiting & 2 \\
\hline \multirow{3}{*}{ Local signs } & $\begin{array}{l}\text { Muscular protection in the right iliac } \\
\text { fossa }\end{array}$ & 1 \\
\cline { 2 - 3 } & $\begin{array}{l}\text { Blumberg's sign }(+) \\
\end{array}$ & \\
\hline
\end{tabular}




\begin{tabular}{|c|c|c|}
\hline & Increased temperature & 1 \\
\hline \multirow{2}{*}{$\begin{array}{l}\text { Laboratory } \\
\text { findings }\end{array}$} & Leukocytosis & 2 \\
\hline & Left shift of the leukocyte formula & 1 \\
\hline Total points & & 10 \\
\hline
\end{tabular}

Data analysis; Discrete data (variables) are presented as absolute values and percentage values Categorical variables are expressed in the respective frequencies and percentages. The data are presented in different tables and graphs. (See table 2)

Table 2. Schematic representation of the cases included in the study

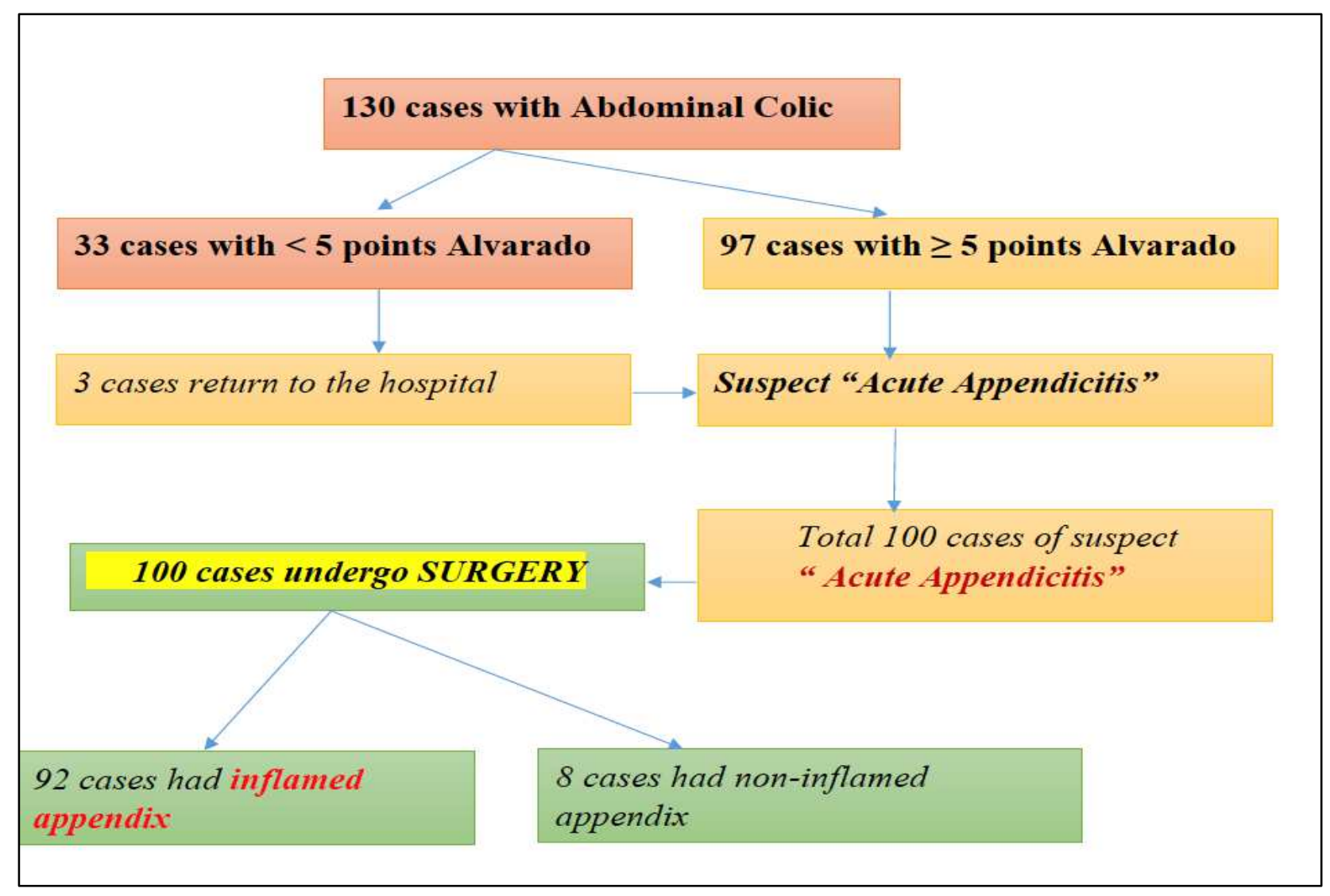

\section{Results}

Of the 100 suspected AA cases, the gender distribution was approximately 1:1 and exactly 52 males and 48 females. All recorded patients ranged in age from 14 to 61 years. Of these, 40 patients belonged to the age group of 14-21 years old, 32 patients belonged to the age group of 21-31 years old, and 28 patients belonged to the group of 41-61 years old. So, the predominant age group was 14-21 years old with $40 \%$.

The main symptoms of the patients in our study at the time of presentation to the emergency department was as follow; in $74 \%$ of cases presented with nausea or vomiting, in $60 \%$ of cases presented with migratory pain or the Kocher sign, and in $46 \%$ of cases presented with anorexia. (See table 3) 
In according of the local signs of 100 cases of suspect AA was as follow; in $100 \%$ of cases presented muscular defense in the Right Iliac Fossa (RIF), in 96\% of cases presented the Blumberg's sign (rebound tenderness), and in $64 \%$ of cases presented fever. The laboratory findings of 100 cases of suspect AA was as follow; in $90 \%$ of cases presented leukocytosis and in $88 \%$ of cases presented neutrophils. These data are shown graphically below.

\section{Table 3. Distribution of Clinical Data}

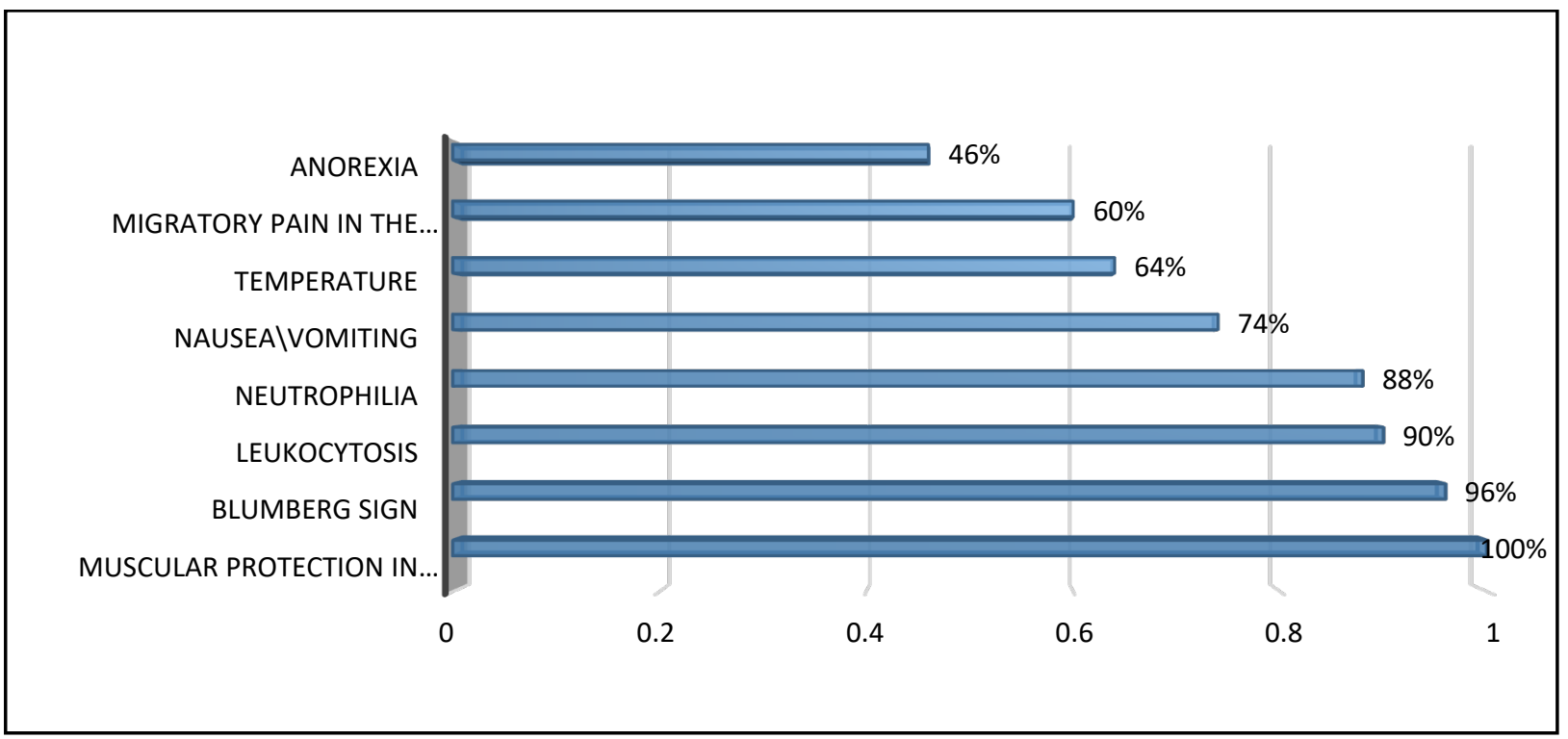

On the basis of symptoms, local signs and laboratory findings we determined the outcome of the Alvarado score for each patient. Of the 100 patients, 20 resulted in $<7$ Alvarado points and 80 of them resulted in $\geq 7$ Alvarado points. (1-4 points - 3 patients; $5-6$ points - 17 patients; $7-10$ points 80 patients)

In more detail, the analysis by Alvarado score is as follows (See table 4):

\begin{tabular}{|c|c|}
\hline Alvarado Score & Nr. of patients \\
\hline 4 points & 3 \\
\hline 5 points & 9 \\
\hline 6 points & 8 \\
\hline 7 points & 31 \\
\hline 8 points & 27 \\
\hline 9 points & 10 \\
\hline 10 points & 12 \\
\hline
\end{tabular}

Table 4. Distribution of Alvarado Score values

The mean of was 7,48 points. In the 7-10-point group, which is considered according to the Alvarado Algorithm suitable for surgical intervention, there were 80 patients.

So, according to AS, of the 100 cases with suspected Diagnosis AA, 80 would be sent for surgery. The remainder, in 20 cases, would not undergo surgery (at least not at the first moment). Of these 20 cases, according to the Alvarado Algorithm, 3 of them (with points 1-4) could be sent home and 17 of them had to be observed.

Let's compare the results of AS with how these cases were managed in the surgical emergency in our article. Unlike the AS, all 100 cases underwent surgery. However, not all cases resulted in the diagnosis of AA at the end of the intervention. The final diagnosis was made through the macroscopic 
view of the surgical specimen. Of the 100 cases that underwent surgery, 92 of them resulted in inflamed appendix, while 8 of them resulted in non-inflamed appendix. The relation of AS to the macroscopic appearance of the surgical specimen is shown in the following graph and table. (See table 5)

Table 5. Distribution of Alvarado Score values

and macroscopic appearance of the surgical specimen

\begin{tabular}{|c|c|c|}
\hline $\begin{array}{c}\text { Alvarado } \\
\text { Score }\end{array}$ & $\begin{array}{c}\text { Inflamed } \\
\text { appendix }\end{array}$ & $\begin{array}{c}\text { Non-inflamed } \\
\text { appendix }\end{array}$ \\
\hline 4 & 0 & 3 \\
\hline 5 & 7 & 2 \\
\hline 6 & 7 & 1 \\
\hline 7 & 30 & 1 \\
\hline 8 & 26 & 1 \\
\hline 9 & 10 & 0 \\
\hline 10 & 12 & 0 \\
\hline Total & 92 & 8 \\
\hline
\end{tabular}

What should be the appropriate boundary AS based on our data? By appropriate boundary we mean the score of Alvarado that serves as the boundary to divide the cases presented in those with inflamed appendix and those with non-inflamed appendix. We are first going to test a "cut off" (or limit) of 7 AS points. Taking the 7point limit, we mean that cases $\geq 7$ points will have acute appendicitis and those with $<7$ points will not have acute appendicitis. We evaluate the accuracy of this assertion based on our study. Can we say that if $\mathrm{AS} \geq 7$ points, the patient has AA? and Can we say that if $<7$ points, the patient has not AA? (See table 6)

Table 6. The relation between the macroscopic view and the Alvarado points where 7 points are used as a limit

\begin{tabular}{|l|c|c|}
\hline $\begin{array}{c}\text { Alvarado } \\
\text { scoring }\end{array}$ & $\begin{array}{c}\text { Inflamed } \\
\text { appendix }\end{array}$ & $\begin{array}{c}\text { Non-inflamed } \\
\text { appendix }\end{array}$ \\
\hline$\geq 7$ points & 78 & 2 \\
\hline$<7$ points & 14 & 6 \\
\hline Total & 92 & 8 \\
\hline
\end{tabular}

To determine if this "cut off" would be appropriate, we have to determine the: Sensitivity; Specificity Positive predictive value; Negative predictive value; Diagnostic accuracy.

In total we have 100 cases from which 92 were confirmed with AA and 8 of them had non-inflamed appendix. By taking the limit of 7 points AS to determine the presence or not of AA, we have 80 cases with AA and 20 cases without AA. But we also have to take into account the values of Table 4 (Table 4: Relation between Alvarado points and macroscopic view) and Table 5 (Table 5: Relation between macroscopic view and Alvarado points where 7 points are used as "cut off") where from the 80 cases that had $\geq 7$ points Alvarado, 78 of them had indeed inflamed appendix and 2 of them had noninflamed appendix.

Also, from the 20 cases of the group with $<7$ points, 14 had indeed inflamed appendix and 6 of them had non-inflamed appendix. 
So, in this way we can define cases that are True Positive (TP), False Positive (FP), False Negative (FN), True Negative (TN). We have 78 TP cases, 2 FP cases, 6 TN cases and 14 cases FN. (See table 7)

Table 7. Distribution of AS points as predict values

\begin{tabular}{|c|c|c|c|c|}
\hline & \multicolumn{2}{|c|}{ Acute Appendicitis (AA) } & \\
\hline & & $\begin{array}{c}\text { Positive for } \mathbf{A A} \\
\quad(\text { Has } A A)\end{array}$ & $\begin{array}{l}\text { Negative for AA } \\
\text { (Doesn't have AA) }\end{array}$ & \\
\hline \multirow{3}{*}{$\begin{array}{l}\text { Results of } \\
\text { Alvarado } \\
\text { Score }(A S)\end{array}$} & Positive for AA & $78(T P)$ & $2(F P)$ & $\begin{array}{c}80 \text { (Has } A A \text { based on } \\
\text { the } A S \text { test) }\end{array}$ \\
\hline & Negative for AA & $14(F N)$ & $6(T N)$ & $\begin{array}{l}20 \text { (Doesn't have } A A \\
\text { based on the AS test) }\end{array}$ \\
\hline & Total & 92 with $A A$ & 8 without $A A$ & 100 \\
\hline
\end{tabular}

We use the same formulas to determine to explain our logic:

Sensitivity $=\frac{\mathrm{TP}}{\mathrm{TP}+\mathrm{FN}} \times 100 \%=84.8 \%$

Specificity $=\frac{\mathrm{TN}}{\mathrm{TN}+\mathrm{FP}} \times 100 \%=75 \%$

Positive predictive value $(\mathrm{PPV})=\frac{\mathrm{TP}}{\mathrm{TP}+\mathrm{FP}} \times 100 \%=97,5 \%$

Negative predictive value $(\mathrm{NPV})=\frac{\mathrm{TN}}{\mathrm{TN}+\mathrm{FN}} \times 100 \%=30 \%$

Accuracy $=\frac{\mathrm{TP}+\mathrm{TN}}{\mathrm{TP}+\mathrm{TN}+\mathrm{FP}+\mathrm{FN}} \times 100 \%=84 \%$

Now we are going to examine the cut off of 5 points AS. The same procedure should also be performed for the "cut off" of 5 points, if we consider the appropriate limit as 5 points.

By a 5-point limit, we mean that cases with $\geq 5$ points have AA or need to be observed as they may develop AA later, while cases with $<5$ points need no observation or referral to a surgeon and can be sent in home.

Can we say that if $\mathrm{AS} \geq 5$ points, the patient has AA? and Can we say that if $<5$ points, the patient has not AA? (See table 8) 
Table 8. The relation between the macroscopic view and

the Alvarado points where 5 points are used as "cut off"

\begin{tabular}{|c|c|c|}
\hline $\begin{array}{c}\text { Alvarado } \\
\text { score }\end{array}$ & $\begin{array}{c}\text { Inflamed } \\
\text { appendix }\end{array}$ & $\begin{array}{c}\text { Non-inflamed } \\
\text { appendix }\end{array}$ \\
\hline$\geq 5$ points & 92 & 5 \\
\hline$<5$ points & 0 & 3 \\
\hline Total & 92 & 8 \\
\hline
\end{tabular}

So, considering "cut off" of 5 AS points, we can define the TP, FP, FN and TN cases. We have 92 TP cases, 5 FP cases, 3 True Negative cases and 0 FN cases.

We use the same formulas to determine to explain our logic: Sensitivity; Specificity; PPV; NPV; Diagnostic accuracy.

Sensitivity $=\frac{\mathrm{TP}}{\mathrm{TP}+\mathrm{FN}} X 100 \%=100 \%$

Specificity $=\frac{\mathrm{TN}}{\mathrm{TN}+\mathrm{FP}} \times 100 \%=37,5 \%$

Positive predictive value $(\mathrm{PPV})=\frac{\mathrm{TP}}{\mathrm{TP}+\mathrm{FP}} \times 100 \%=94,8 \%$

Negative predictive value $(N P V)=\frac{\mathrm{TN}}{\mathrm{TN}+\mathrm{FN}} X 100 \%=100 \%$

Accuracy $=\frac{\mathrm{TP}+\mathrm{TN}}{\mathrm{TP}+\mathrm{TN}+\mathrm{FP}+\mathrm{FN}} X 100 \%=95 \%$

Table 9. Comparison of the boundaries using the statistical indicators

\begin{tabular}{|l|c|c|}
\hline Statistical indicator & $\begin{array}{c}\text { Cut off 7 points } \\
\text { Alvarado }\end{array}$ & $\begin{array}{c}\text { Cut off 5 points } \\
\text { Alvarado }\end{array}$ \\
\hline Sensitivity & $84,8 \%$ & $100 \%$ \\
\hline Specificity & $75 \%$ & $37,5 \%$ \\
\hline Positive predictive value & $97,5 \%$ & $94,8 \%$ \\
\hline Negative predictive value & $30 \%$ & $100 \%$ \\
\hline Accuracy & $84 \%$ & $95 \%$ \\
\hline
\end{tabular}

Using the 7 points AS as a cut off, the test has a sensitivity of $84.8 \%$ which is considered moderate high but still lower than when using the 5 points Alvarado as a cut off. It also has a $75 \%$ specificity which is considered moderate but higher than the second case. There are PPV and NPVwith 97.5\% and 30\%, respectively, where PPV is higher than in the second case while NPV is lower than in the second case. The diagnostic accuracy is 34\%, lower than the second case. (See table 9)

Using 5 points AS as a cut off, the test has a $100 \%$ sensitivity which is the maximum. It also has a specificity of $37.5 \%$ which is considered low and lower than in the first case. There are positive and 
negative predictive values with $94.8 \%$ and $100 \%$, respectively, where PPV is lower than in the first case while NPV is higher. The diagnostic accuracy is $95 \%$, higher than in the first case.

Using the 7 points Alvarado as a cut off has higher specificity and higher PPV.

Using 5 points Alvarado score as a cut off has higher sensitivity, NPV and accuracy.

Sensitivity determines the ability of a test or study to detect sick patients. Since the second case has $100 \%$ sensitivity, it means that this case detects all sick individuals.

Specificity determines the ability of a test or study to detect non-diseased individuals. AS with a 7point criteria has this capability, while the second case presents a low capability in this regard.

A positive predictive value determines how many sick individuals on the test are actually sick. This value is best where AS uses a 7-point criterion.

The negative predictive value determines how many healthy individuals on the test are actually healthy. AS with a 5-point criterion has this capability, while the first case has low capability in this regard. It is important to note that PPV and NPV values depend on the prevalence of the disease. AA is a prevalent disease in contemporary medicine.

Diagnostic accuracy determines how many of the cases defined as ill and not ill by the test or study are realistically so. AS with a 5 point criterion has this capability.

\section{Results of appendectomies}

All the cases studied were referred to surgical intervention. Recall table 3 again (See table 10, 11, 12) The relation between AS and macroscopic view). Of the 100 cases that underwent surgery, 92 of them had inflamed appendix macroscopically and 8 of them had non-inflamed appendix. So, 8 appendectomies have been unnecessary.

Table 10. Distribution of appendectomies when using as "cut off" 7 points Alvarado.

\begin{tabular}{|c|c|c|}
\hline $\begin{array}{c}\text { Points } \\
\text { Alvarado }\end{array}$ & $\begin{array}{c}\text { using as "cut off" } 7 \text { points Alvarado. } \\
\text { Appendectomy }\end{array}$ & $\begin{array}{c}\text { Negative } \\
\text { Appendectomy }\end{array}$ \\
\hline$<7$ & 14 & 6 \\
\hline$\geq 7$ & 78 & 2 \\
\hline Total & 92 & 8 \\
\hline
\end{tabular}

Table 11. Distribution of appendectomies

\begin{tabular}{|c|c|c|}
\hline $\begin{array}{c}\text { when using as "cut off" } \\
\text { Points } \\
\text { Alvarado }\end{array}$ & $\begin{array}{c}\text { Positive } \\
\text { Appendectomy }\end{array}$ & $\begin{array}{c}\text { Negative } \\
\text { Appendectomy }\end{array}$ \\
\hline$<5$ & 0 & 3 \\
\hline$\geq 5$ & 92 & 5 \\
\hline Total & 92 & 8 \\
\hline
\end{tabular}

In conclusion, we can say that in our study negative appendectomy is not a major problem ( $8 \%$ in total). Even smaller is the negative appendectomy in the $\geq 7$ points AS group, $2.5 \%$ and $5 \%$ when we have $\geq 5$ points. This may also be explained by the fact that these patients come to UHT usually recommended by a primary or secondary center.

Diagnostic significance of the group with a maximum score of 9-10 points.

In the group with 9-10 points we have a total of 22 cases. Of the 22 cases all resulted in inflamed appendix in the macroscopic appearance of the surgical specimen.

In this group, it is $100 \%$ certain that the cases involved will have AA. 


\section{Discussion}

In our study we initially had 130 cases included which were admitted to the surgical emergency with Abdominal Colic. Of these 97 of them, who scored $\geq 5$ points after AS, were suspended for AA. Of the other 33 cases, which were not suspected for AA, resulted in $<5$ points, and 3 of them, who had 4 points each at the first time they presented themselves to the surgical emergency, returned within 24 hours in ED.

The diagnosis of AA was also suspected for them.

All 100 cases with suspected AA underwent surgery, which resulted in 92 of them actually having AA and 8 of them not having inflamed appendix.

Patients who returned had a fever, a finding that was missing the first time they came to emergency. It is also known in the literature that the temperature can be normal up to the first 6 hours. $(12,13)$.

In our study, we found that out of 100 cases, the distribution by gender represents a slight predominance of males. The male / female ratio was approximately 1.08:1. Even in the literature there is a slight predominance of males compared to females, which ranges from 1.4: 1. $(12,14)$. The predominant age group observed in our study was $14-21$ years old with $40 \%$ of cases. Other studies, such as the one by Hagos et all have concluded that the most predominant age group in AA is $10-20$ years old. (15)

In terms of local signs, the most important data has been the muscular protection in right iliac fossa that was observed in $100 \%$ of patients. This is consistent with the results of many other studies such as those by authors Zyluk et all where this clinical sign has been observed in all cases. (16)

In relationships of symptoms, the most important indication was nausea / vomiting in $74 \%$ of cases. This data is also noted in literature such as Mike K. Liang's et all when nausea or vomiting is observed in over half of the cases and occurs several hours after abdominal pain. (17)

Of the laboratory findings, the most important finding was leukocytosis that was observed in $90 \%$ of patients. In some studies, leukocytosis was observed in most patients but other clinical data are better indicators than that for AA. $(18,19,20)$

The most important variable provided by the determination of symptoms, local signs and laboratory findings for each case is the AS. In our study $3 \%$ of the cases belonged to the 1-4point group, $17 \%$ of cases to the 5-6-point group and $80 \%$ of cases to the $7-10$-point group.

We focused on determining the most appropriate criterion ("cut off"). By criterion we meant the appropriate Alvarado dot to divide the cases into "with inflammatory appendix" and those with "non-inflammatory appendix", so, with AA diagnosis and not with AA diagnosis.

When we were using the AS 7-point criterion, values, sensitivity, specificity, positive, negative and efficiency predictive values were derived using the tables and graphs presented. It was concluded that these values were $84.8 \%$, respectively; $75 \% ; 97.5 \%$; $30 \%$; and $84 \%$.

Similar values for statistical indicators when the cut off was 7 points AS were observed in other studies. Thus, in a study by authors Ohle et all, sensitivity and specificity values were $82 \%$ and $81 \%$, respectively. (11)

The same analysis was done for $5 \mathrm{AS}$ as well and the sensitivity, specificity, positive, negative predictive values and statistical efficiency were $100 \% ; 37.5 \% ; 94,8 \% ; 100 \%$ and $95 \%$.

Such similar values for statistical indicators when the cut off was 5 points AS were observed in other studies. Thus, in a study by Saidi et al, sensitivity and specificity values were $99 \%$ and $43 \%$, respectively. (21)

As far as the criterion being 7-points AS is concerned, this case has higher specificity, which means that it has a greater ability to detect non-sick individuals. It also has a higher VPP, which means that using this test has a greater chance that the patients discovered by it will be really 
sick. The problem is that this case has low sensitivity, which means that it fails to detect all the patients.

When we were using Alvarado points 5 criteria, we are dealing with a test that detects all AA patients because it has $100 \%$ sensitivity. The diagnostic efficiency is $100 \%$ maximum, which means that the sick and unhealthy cases that the test has detected are true. The problem is that this test fails to detect all individuals who do not have AA, as it has a low specificity. On the other hand, all those that this test does with AA do not really have the disease as NPV is $100 \%$. Use Alvarado points $=7$ as criterion has higher specificity and higher PPV. Use as a 5 point AS criterion has higher sensitivity, NPV and efficiency.

Both cases were deficiencies in statistical indicators, but the most deficient is the case where 7points are taken as a criterion.

A very important element to consider is the type of pathology. In our case we are dealing with a pathology which, if not rigorously managed, presents serious complications. It is at this point that the importance of high sensitivity tests emerges. A high sensitivity test is important when dealing with a serious but treatable disease, such as AA. This is because this test detects all the patients who will then be treated. In our case the highest sensitivity is when using the Alvarado 5-point criterion.

In conclusion, we can also say that in the case of using Alvarado points $=7$ as a criterion, this criterion alone cannot accept or exclude the possibility of surgical intervention, a statement also noted in the study by Ohle et all (11), however, it should be noted that AS $\geq 7$ scoring is needed to identify those cases at high risk for acute appendicitis requiring surgical consultation or further diagnostic imaging.

High Alvarado points (9-10 points) can serve to help determine the need for urgent appendectomy, especially for young surgeons. This is based on many studies such as those by authors Merhi et all, where it was also noted and in our study that the 9-10 point group had no false-positive case, so they all had AA diagnosis.(22)

Another aspect to consider is the level of negative appendectomy. By negative appendectomy we mean the realization of appendectomy without actually having AA diagnosis. In our study it was $8 \%$, that is, relatively low. In the case of the 7-point criterion, negative appendectomy is $30 \%$ when $\mathrm{AS}<7$ points and $2.5 \%$ when $\mathrm{AS} \geq 7$ points. When using as a 5-point AS criterion, negative appendectomy was $5 \%$ when $\mathrm{AS} \geq 5$ points. AS can be used as a tool to reduce negative appendectomy. Many studies have shown negative appendectomy rates as $13.3 \%, 15.6 \%$ and $16.2 \%$ of cases . (23)

In our study, lower values are observed because most cases are delegated to UHC from primary or secondary health centers, unlike studies performed elsewhere where the cases may initially appear in a surgical emergency.

In terms of US (Ultrasonography) sensitivity in our study, it was $49 \%$, ie a low sensitivity. Data from other studies, such as those by authors Seung-Hum Yu et all, and the literature indicate 86\% sensitivity.(24) However, this depends on many factors such as doctor's experience, increased intestinal gas, obesity, anatomical variations of appendicitis, etc.

Only 6 patients (7-8 points) underwent CT (Computed Tomography) examination (patients in whom clinical presentation was suspected) and CT was diagnostic in all patients. High diagnostic value of CT was also observed in others such as authors Evrimler et all where sensitivity and specificity are $94 \%$ and $95 \%$ respectively. 66 The low number of high-risk patients undergoing CT can be explained by the cost of this examination or the lack of its access at all times.

Only 6 patients (7-8 points) underwent CT examination (patients in whom clinical presentation was suspected) and CT was diagnostic in all patients. High diagnostic value of CT was also observed in others such as Evrimler et all where sensitivity and specificity are $94 \%$ and $95 \%$ respectively.(25)

The low number of high-risk patients undergoing CT can be explained by the cost of this examination or the lack of its access at all times. 


\section{Conclusions}

Clinical findings and physician experience continue to be of a major importance in the diagnosis of AA. Today the diagnosis can be aided by the use of imaging modalities such as ultrasound or CT, Magnetic resonance imaging (MRI), diagnostic laparoscopy, etc.

However, in underdeveloped or developing countries where the decision to operate or not depends on clinical judgment, AS can serve as a meticulous and consistent design tool to exclude appendicitis and identify those at high risk who would benefit from hospital admission.

Secondly AS may serve as a simplified tool for the emergency physician as a more predictive tool in abdominal emergency in general and for AA in particular.

- In the case of AA, which is a serious but a treatable disease, it would be important to find a high sensitivity scoring system that detects all patients. From our study, the use of a 5 point AS criterion made this scoring system $100 \%$ sensitive. So the 5-point criterion AS can be used as a means of detecting individuals who have AA or may develop AA later.

- On the other hand, the AS with a 7-point criterion is not sufficient to "rule" so to establish the need for surgery alone.

A very important element to consider is the type of the pathology. In our case we are dealing with a pathology which, if not rigorously managed, presents serious complications. It is at this point that the importance of high sensitivity tests emerges. A high sensitivity test is important when dealing with a serious but treatable disease, such as AA. This is because this test detects all the patients who will then be treated. In our case the highest sensitivity is when using the Alvarado 5-point criteria.

High AS (9-10 points) can serve to help determine the need for urgent appendectomy, especially for young surgeons, because all patients with this AS are actually patients with inflamed appendix.

\section{Abbreviations}

Acute Appendicitis - AA

Alvarado Score - AS

Right Iliac Fossa - RIF

True Positive - TP

False Positive - FP

False Negative - FN

True Negative - TN

Positive Predictive Value - PPV

Negative Predictive Value - NPV

University Hospital Centre - UHT

Ultrasonography - US 
Computed Tomography - CT

Magnetic Resonance Imaging - MRI

\section{Ethical Approval and Consent to participate.}

Not applicable in this section.

\section{Consent for publication.}

In our text don't include any individual person's data in any form (including individual details, images or videos), Not applicable in this section.

Acknowledgements The authors are very grateful to the staffs of the University Hospital of Trauma in Tirana, who have been generous and supportive throughout the conduction of this Study.

\section{Funding}

This research did not use any internal or external funds.

\section{Availability of data and materials}

Please contact the authors for data requests.

\section{Authors' contributions}

AD designed the study and methodology, participated in gathering the data, and conducted the analysis. AGj provided the literature review, participated in the data collection and contributed to the statistical analysis. KH evaluated the diagnosis and complications and provided important insights for the data classification. SD \& HB contributed to the data collection and provided systematic assistance in crafting the analysis. AD contributed to the data classification and the interpretation of the results. All authors read and approved the final manuscript.

\section{Competing interests}

The authors declare that they have no competing interests.

\section{Author details}

Agron DOGJANI MD, MSc, PhD, FACS. FISS ${ }^{1 *}$, Kastriot HAXHIREXHA MD, $\mathrm{PhD}^{2}$ : Arben GJATA MD, $\mathrm{PhD}^{3}$, Sabina DOGJANI MD ${ }^{4}$, Hysni BENDO MD ${ }^{4}$,

${ }^{1}$ Associate Professor of Surgery, University Hospital of Trauma, Lecturer at University Medicini of Tirana, ALBANIA. Email; agrondogjani@yahoo.com ; agrondogjani@gmail.com

${ }^{2}$ Professor of Surgery at State University of Tetovo, General Surgeon at Clinical Hospital of Tetovo, RN of MACEDONIA. Email - dr.kastriot@gmail.com

${ }^{3}$ Professor of Surgery at Lecturer at University Medicini of Tirana, ALBANIA. Email arbengjata@msn.com

${ }^{4}$ General Physician National Centre of Medical Emergency, Tirana, ALBANIA. Email dogjanisabina@gmail.com

4 General Physician National Centre of Medical Emergency, Tirana, ALBANIA. Email hysnibendo@gmail.com 
*Corresponding Author: Agron Dogjani MD, MSc, PhD, FACS, FISS, Associate Professor of Surgery, University Hospital of Trauma, Lecturer at University Medical of Tirana, ALBANIA. Email; agrondogjani@yahoo.com ; agrondogjani@gmail.com Mobile +355692056123

\section{Reference}

1. Schwartz's Principles of Surgery $10^{\text {th }}$ Edition, Mike K. Liang, Roland E. Anderson, Bernard M. Jaffe, David H. Berger, p 1241

2. Presidential Address: a history of appendicitis. With anecdotes illustrating its importance. Williams GR. Ann Surg. 1983 May;197(5):495-506.

3. Appendicitis $3^{\text {rd }}$ Edition, Philadelphia, P Blakiston's Son \& Co; Deaver JB, 1905

4. Maingot's Abdominal Operations 8th Edition Volume 2, Michael J. Zinner, Stanley W. Ashley, O. Joes Hines, $\mathrm{p}$ - 1255

5. Surgical diseases 2013, Nikollaq Kaçani, p 147

6. The prognosis and modern treatment of appendicitis 1899, Power D, p - 1467- 1470

7. Acute Abdominal Pain: Physiology of the Acute Abdomen 1998. Meyers S, Miller TA, p 641-667.

8. Bailey \& Love's Surgery 27th Edition, Norman S. Williams, P. Ronnan O'Connell, Andrew W. Mc Caskie, $\mathrm{p}-1300$

9. Serotonin and its possible role in the painful non-inflamed appendix 1983, Dhillon AP, Rode J. Diagn Histopathol. 1983 Jul-Dec;6(3-4):239-46.

10. Appendectomy and protection against ulcerative colitis 2001, Andersson RE, Olaison G, Tysk C, Ekbom A, N Engl J Med. 2001 Mar 15;344(11):808-14.

11. The Alvarado score for predicting acute appendicitis: a systematic review, Robert Ohle, Fran O'Reilly, Kirsty K O'Brien, Tom Fahey, Borislav D Dimitrov - BMC Medicine 2011, 9:139 $\mathrm{http}: / / \mathrm{www} \cdot$ biomedcentral.com/1741-7015/9/139

12. Is appendicitis more common in males or females, E medicine, Medscape Sandy Craig https://emedicine.medscape.com/article/773895-overview

13. Evidence-based emergency medicine/rational clinical examination abstract. Does this adult patient have appendicitis? Yeh B. Ann Emerg Med. 2008 Sep. 52(3):301-3

14. Misdiagnosed Appendicitis in Children, Kastriot Haxhirexha, Agron Dogjani, Lutfi Zylbehari, Ferizate Dika -Haxhirexha; AJTES (2018) 2: p 99-104; https://doi.org/10.32391/ajtes.2018.2.2.005

15. Pattern of acute appendicitis in Mekelle Ethiopia 2014, Hagos M. Ethiop Med J. 2014 Jul; 52(3):113-8.

16. An analysis of factors influencing accuracy of the diagnosis of acute appendicitis 2011, Zyluk A, Ostrowski P. Pol Przegl Chir. 2011 Mar;83(3):135-43. doi: 10.2478/v10035-011-0021-9.

17. Schwartz's Principles of Surgery $10^{\text {th }}$ Edition, Mike K. Liang, Roland E. Anderson, Bernard M. Jaffe, David H. Berger, p 1243.

18. Clinical value of total white blood cells and neutrophil counts in patients with suspected appendicitis: retrospective study 2012, Zuhoor K Al-gaithy World J Emerg Surg. 2012 Oct 2;7(1):32. doi: 10.1186/1749-7922-7-32.

19. The Diagnostic Value of C-Reactive Protein and Total Leucocytes Count... Ferizate Dika Haxhirexha, Agron Dogjani, Ledia Kaçi, Lutfi Zylbeari, Kastriot Haxhirexha. AJTES (2018) 2: p 118-124; https://doi.org/10.32391/ajtes.2018.2.2.008

20. The Diagnostic Role of Hyperbilirubinemia in Complicated and Non -complicated Appendicitis; Valon Zejnullahu, Rozalinda Isjanovska, Besnik Bicaj, Vjosa A. Zejnullahu, Astrit R. Hamza, Viktoria Caloska Ivanova AJTES (2018) 2: 151-162 https://doi.org/10.32391/ajtes.2018.2.2.012

21. Role of Alvarado score in diagnosis and treatment of suspected acute appendicitis 2000, Saidi RF, Ghasemi M. Am J Emerg Med. 2000 Mar;18(2):230-1.

22. Comparison of Alvarado Score Evaluation and Clinical Judgment in Acute Appendicitis, Bassem Abou Merhi, Mahmoud Khalil, Nabil Daoud, Med Arch. 2014 Feb; 68(1): 10-13. Published online 2014 Feb 20. doi: $10.5455 /$ medarh.2014.68.10-13

23. Negative appendicectomy rate as a quality metric in the management of appendicitis: impact of computed tomography, Alvarado score and the definition of negative appendicectomy 2011, JG Mariadason, WN Wang, MK Wallack, A Belmonte, and H Matari Ann R Coll Surg Engl. 2012 Sep; 94(6): 395-401.doi: 10.1308/003588412X13171221592131 
24. Ultrasonography in the Diagnosis of Appendicitis: Evaluation by Meta-analysis 2005, Seung-Hum Yu, Chun-Bae Kim, Joong Wha Park, Myoung Soo Kim,David M. Radosevich Korean J Radiol. 2005 OctDec; 6(4): 267-277. Published online 2005 Dec 31. doi: 10.3348/kjr.2005.6.4.267

25. Computed Tomography (CT) Findings of a Diagnostic Dilemma: Atypically Located Acute Appendicitis 2016, Sehnaz Evrimler, Irfan Okumuser, Nermin Unal, Pol J Radiol. 2016; 81: 583-588. Published online 2016 Dec 4. doi: 10.12659/PJR.898880 
